\title{
JOGO DIDÁTICO COMO PROPOSTA NO ENSINO DE BOTÂNICA: DESENVOLVENDO METODOLOGIA INOVADORA COM ALUNOS DE UMA ESCOLA ESTADUAL DE FLORIANO (PI)
}

\section{ENSEÑANZA DE JUEGO COMO SE PROPONE EN EDUCACIÓN BOTANICA: DESARROLLO MÉTODO INNOVADOR CON ESTUDIANTES DE UNA ESCUELA ESTATAL FLORIANO (PI)}

\section{GAME TEACHING AS PROPOSED IN BOTANICA EDUCATION: DEVELOPING INNOVATIVE METHOD WITH STUDENTS OF A STATE SCHOOL FLORIANO}

(PI)

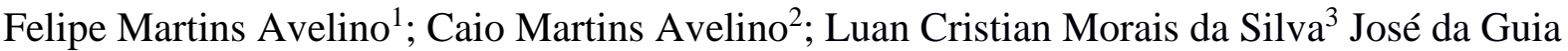 \\ da Conceição Ferreira ${ }^{4}$; Michelle Mara de Oliveira Lima ${ }^{5}$
}

DOI: https://doi.org/10.31692/978-65-991061-3-2.1-13

\begin{abstract}
RESUMO
A Botânica é o ramo da biologia que estuda as plantas. A dificuldade de despertar nos alunos o interesse pela Botânica é um desafio em algumas salas de aula, principalmente se a proposta de ensino for baseada em métodos convencionais, restritos aos livros didáticos e aulas expositivas. Os desafios do Ensino de Botânica podem ser atribuídos à falta de confiança e capacitação dos professores acerca dos conteúdos de botânica. A utilização de recursos que proporcione uma aplicação lúdica do conteúdo torna-se de suma importância pois os alunos podem apresentar melhor receptividade e mais interesse pela botânica. O objetivo do trabalho foi analisar a aplicação e avaliação de um jogo didático, denominado "Velha Botânica", como recurso didático para o ensino e aprendizagem dos grupos vegetais presentes na botânica e suas principais características. O jogo foi aplicado com 24 alunos no $2^{\circ}$ ano do ensino médio de uma escola estadual de Floriano (PI). Os dados foram coletados através aplicação de um questionário antes(pré-teste) e após (pós-teste) à aplicação do jogo. Nos resultados, observou-se que o entendimento dos alunos sobre as características dos grupos de plantas avasculares e vasculares foi bastante positivo, principalmente quanto as diferenças básicas dos grupos de plantas e a importância do fruto como característica evolutiva das angiospermas. A maioria dos alunos conseguiu alcançar o objetivo de compreende e apreender o conteúdo de uma maneira divertida e lúdica. Os alunos destacaram também a importância da contribuição do jogo didático para sua aprendizagem no conteúdo de botânica.
\end{abstract}

Palavras-Chave: Ensino, Jogo, Aprendizagem.

\section{RESUMEN}

La botánica es la rama de la biología que estudia las plantas. La dificultad para despertar el interés de los estudiantes en la botánica es un desafío en algunas aulas, sobre todo si la propuesta de enseñanza se basa en métodos convencionales restringidas a los libros de texto y

\footnotetext{
${ }^{1}$ Licenciatura em Ciências Biológicas, Instituto Federal do Piauí - Campus Floriano, Felipe1.3000@hotmail.com ${ }^{2}$ Licenciatura em Ciências Biológicas, Instituto Federal do Piauí - Campus Floriano, caiomartins1996@hotmail.com

${ }^{3}$ Licenciatura em Ciências Biológicas, Instituto Federal do Piauí - Campus Floriano, luancristianmorais@gmail.com

${ }^{4}$ Licenciatura em Ciências Biológicas, Instituto Federal do Piauí - Campus Floriano, josedaguiag30@outlook.com

${ }^{5}$ Mestre em Ensino de Biologia, Instituto Federal do Piauí - Campus Floriano, michellelima@ifpi.edu.br
} 
conferencias. Los retos de la enseñanza Botánica pueden atribuirse a la falta de confianza y la formación de los profesores sobre el contenido botánico. El uso de los recursos para proporcionar una aplicación lúdica de contenido se convierte en muy importante porque los estudiantes pueden proporcionar una mejor capacidad de respuesta y más interés por la botánica. El objetivo fue analizar la implementación y evaluación de un juego educativo llamado "Viejo Botánica" como recurso didáctico para la enseñanza y el aprendizaje de los grupos de plantas en la botánica y sus principales características. El juego se aplicó a 24 estudiantes en el segundo año de la escuela secundaria a una escuela estatal de Floriano (PI). Los datos fueron recolectados mediante la aplicación de un cuestionario antes (pretest) y después (post-test) la aplicación del juego. En los resultados, se observó que los estudiantes la comprensión de las características de los grupos de plantas avasculares y vasculares fue muy positiva, especialmente en relación con las diferencias básicas de los grupos de plantas y la importancia de la fruta como rasgo evolutivo de las angiospermas. La mayoría de los estudiantes lograron alcanzar el objetivo de entender y comprender el contenido de una manera divertida y lúdica. Los estudiantes también hicieron hincapié en la importancia de la contribución juego didáctico a su aprendizaje de los contenidos de la botânica.

Palabras Clave: Ensenanza, juego, aprendiendo.

\begin{abstract}
Botany is the branch of biology that studies plants. The difficulty to arouse students' interest in the Botany is a challenge in some classrooms, especially if the teaching proposal is based on conventional methods restricted to textbooks and lectures. The challenges of Botany Teaching can be attributed to lack of confidence and training of teachers about the botanical content. The use of resources to provide a playful application of content becomes very important because students can provide better responsiveness and more interest in botany. The objective was to analyze the implementation and evaluation of an educational game called "Old Botany" as a teaching resource for teaching and learning of plant groups in the botany and its main features. The game was applied to 24 students in the 2nd year of high school to a state school of Floriano (PI). Data were collected by applying a questionnaire before (pretest) and after (post-test) the application of the game. In the results, it was observed that students' understanding of the characteristics of avascular and vascular plant groups was very positive, especially regarding the basic differences of plant groups and the importance of the fruit as evolutionary trait of angiosperms. Most students managed to achieve the goal of understand and grasp the content in a fun and playful way. Students also stressed the importance of the didactic game contribution to their learning the contents of botany.
\end{abstract}

Keywords: Teaching, game, learning.

\title{
INTRODUÇÃO
}

A Botânica é o ramo da biologia que estuda os vegetais. Teve início com o estudo sobre plantas medicinais, pois os primeiros registros sobre plantas foram apresentados pelos egípcios e os gregos também deixaram registrados das suas observações sobre os diversos tipos de plantas, há também descrições de plantas e suas aplicações no combate a diferentes tipos de doenças na história (MARTINS-DA-SILVA, 2014). O ensino de botânica é bastante interessante, porém a abordagem meramente descritiva utilizada, na maioria das vezes, pelos professores, pode desestimular os alunos fazendo com que percam o interesse pelo conteúdo (MELO, 2012). Entretanto, estudos recentes afirmam que ao utilizar recursos que propiciem a 
aplicação lúdica do conteúdo, os alunos apresentam melhor receptividade é mais interesse pela botânica (ESTRELA; VIANA; SANTANA, 2017).

De acordo com Arrais, Souza e Masrua (2014), as dificuldades do Ensino de Botânica são atribuídas à falta de confiança dos professores acerca da abordagem do tema. Como discutido por Salatino e Buckeridge (2016), muitos professores tiveram uma formação insuficiente em botânica, a consequência disso são professores sem motivação de nutrir nos seus alunos o aprazer de aprender botânica.

É importante desde do início cultivar o interesse dos alunos pelo aprendizado em botânica. De acordo com Raven (2007), as plantas, participam de nossas vidas de diversas maneiras além de fontes de alimento, nos fornecendo fibras para vestuário, madeira para mobiliário, abrigo e combustível, papel para livros, substâncias para produção de remédios e também o oxigênio que respiramos. $\mathrm{O}$ estudo das plantas ou de botânica nos garantiu melhor compreensão da natureza de toda a vida existem na terra. Portanto, somos completamente dependentes das plantas e por este motivo importância de ensinar o devido valor que as plantas tem no ecossistema (SALATINO; BUCKERIDGE, 2016).

Segundo Melo (2012), a dificuldade de despertar nos alunos o interesse pela Botânica é um desafio em algumas salas de aula, principalmente se a proposta de ensino for baseada em métodos convencionais, restritos aos livros didáticos e aulas expositivas, não surtirá nenhum efeito positivo na aprendizagem dos alunos. Nesse sentido, Araújo (2011), relata que enquanto os professores estiverem duvidosos em relação as aulas expositivas cheias de palavras e definições a serem meramente decoradas pelos alunos o ensino será cada vez mais desinteressante. Portanto, se não houver interesse dos professores em trabalhar novos métodos e técnicas que desenvolva nos alunos um aprender significativo.

De acordo com Silva (2014), o ensino dos conteúdos de botânica e de biologia de modo geral é importante escolher atividades que enalteça a relevância do conteúdo para a pessoa, sendo que é importante que possua o envolvimento do diversos contexto econômico, socioambiental no ensino de botânica e biologia, tal como destacando a utilização das plantas nesses diversos aspectos, permitindo aos estudantes compreender as relações entre o ser humano e a natureza intermediado pela tecnologia.

Muitos autores destacam a importância dos jogos no ensino, como um recurso didático, sendo fundamental no processo de ensino e aprendizagem. Segundo Neves et al. (2014), o lúdico como abordagem na sala de aula, a partir da aplicação de jogos didáticos pode proporcionar novas formas de acesso à informação e de produção de novos conhecimentos, motivando o interesse do aluno a buscar novas maneiras de estudar os conteúdos programáticos, 
colaborando assim, para a melhoria da qualidade do ensino de biologia e botânica no brasil.

Neste sentido, este trabalho propõe o uso de um recurso que procurou proporcionar um contexto lúdico, integrando os grupos vegetais presentes na botânica e suas principais características, para uma abordagem chamativa, no intuito de buscar o interesse do aluno ao assunto apresentado.

\section{FUNDAMENTAÇÃO TEÓRICA}

O ensino biologia é marcado prioritariamente por aulas teóricas e pela exploração subvalorizada e descontextualizada da realidade, construída e reproduzida pelo professor, esta característica uma das principais responsáveis pela continuidade da prática docente tradicional (SANTOS; NETO, 2017). No ensino de Biologia há uma ausência de vinculação entre o que se está sendo abordado na teoria e prática, os conteúdos são tratados de forma distante da realidade dos alunos, com isso o professor precisará promover nos alunos um raciocínio teórico e indagações dos conteúdos presente no seu cotidiano (MELO, 2010).

O ensino de botânica é visto pelos alunos do ensino fundamental e médio como um assunto de difícil compreensão, entediante e fora do contexto moderno. Os alunos não consideram como matéria importante para sua vida, a botânica se tornou lamentavelmente um assunto descartável para os alunos. A cegueira botânica é um termo utilizado para explicar porque os alunos não gostam de botânica, este termo descreve que as pessoas não percebem a importância das plantas para biosfera e o seu cotidiano, e também os aspectos morfológicos e biológicos presentes nas plantas, achando que as plantas são seres inferiores aos animais, ou seja, indignos de alguma atenção (SALATINO; BUCKERIDGE, 2016).

O processo de ensino-aprendizagem em botânica, se desenvolve dentro de um contexto considerado estático, desinteressante e que leva à falta de motivação por parte dos educandos (SALATINO; BUCKERIDGE, 2016). Batista e Araújo (2015), destacam também preocupação em relação aos resultados negativos apresentados no processo de ensino-aprendizagem de botânica. Visto que o professor acaba utilizando-se de um modelo convencional de ensino, de maneira que acaba fugindo da realidade da escola e da vida do aluno (BONFIM et al., 2015).

O ensino da Botânica, bem como uma grande parte dos conteúdos relacionados às disciplinas de Biologia é marcado por diversas barreiras e dentre as mais evidentes encontramse o desinteresse e a falta de motivação dos alunos por esse conteúdo, a falta de desenvolvimento de novas metodologias e de materiais didáticos voltados para o aproveitamento dessa área (MELO, 2012).

Nas aulas de Botânica é evidente a dificuldade dos professores em utilizar recursos 
pedagógicos, onde acaba limitando o poder do conhecimento a ser adquirido pelos estudantes (BONFIM et al., 2015). Logo, os professores apresentam esta dificuldade por não haver uma relação harmônica e proveitosa com os recursos didáticos, porque nãos estão familiarizados a utilizar recursos didáticos para facilitar a aprendizagem dos alunos nos conteúdos de biologia e botânica (NICOLA; PANIZ, 2016).

O professor deve dispor de prática docente que se utilize de pedagogias diferenciadas, visto que o mundo globalizado é nossos alunos anseiam por formas de ensinar mais dinâmicas, atraentes e contextualizadas em que eles sejam os sujeitos ativos desse processo, baseando-se no construtivismo para o processo de ensino e aprendizagem na Educação em Ciências, afim de construir-se um sentido ao conteúdo da disciplina (ARAÚJO, 2013).

O uso de novas tecnologias na educação pode propiciar a quebra de barreiras, além de ajuda no desenvolvimento de novos conhecimentos, havendo a necessidade de focar na formação de educadores para que possam desenvolver novas metodologias de ensino, voltadas para utilização de novas tecnologias de aprendizagem ou desfrutar o máximo da tecnologia que se tem à disposição (DA SILVA; CORREA, 2014).

A simples reproduções de conhecimento na sala de aula não favorece o aprendizado dinâmico dentro da sala de aula, não viabilizado a correta assimilação dos conceitos e sua aplicação em situações de vivências distintas, por parte do discente. Contudo o ensino de Botânica dispõe-se da urgência da necessidade de uma nova prática pedagógica, não se utilizando de modelos e receitas prontas (MOUL; DA SILVA,2017).

O uso de recursos diversificados em sala de aula e a construção de conceitos de pluralismo metodológico acaba tornam-se indispensável, visto que a necessidade é evidente de diversificar os materiais didáticos e modalidades didáticas na sala de aula, propiciando o melhor ensino é motivação dos alunos em relação aos modos de aprender. Assim á possibilita de inserir todos os alunos naquilo que é discutido em sala de aula (SANTANA; CASASCO; SESSA, 2016).

\section{METODOLOGIA}

A metodologia aplicada teve abordagem qualitativa e quantitativa. A pesquisa foi realizada na Escola Estadual Ceti Fauzer Bucar em Floriano, Piaui. A partir da análise dos dados obtidos da pesquisa, verificou-se que quantidade de alunos participantes da pesquisa foi de 24 alunos do $2^{\mathrm{a}}$ ano do ensino médio, sendo que a maioria dos alunos da turma é constituída $62,5 \%$ do sexo feminino é 37,5\% do sexo masculino. Em relação a idade dos alunos observou-se que apresentava idade entre 15 até 19 anos de idade. 
Foi aplicado o pré-questionário para diagnóstico, antes da aplicação do jogo didático sobre botânica. O questionário apresentava perguntas abertas e fechadas com 6 perguntas: 4 eram referentes aos grupos vegetais e suas características e 2 questões referente a metodologia utilizada no trabalho. O jogo "Velha Botânica" executado com os alunos, possuem uma fácil interatividade. Ao iniciar, o jogador é apresentado a uma tela com o nome "velha botânica" e o nome jogar e instruções (Figura 1).

Figura 1- O jogo didático aplicado aos estudantes $2^{\circ}$ série do ensino médio da escola Ceti Fauzer Bucar, Floriano-PI
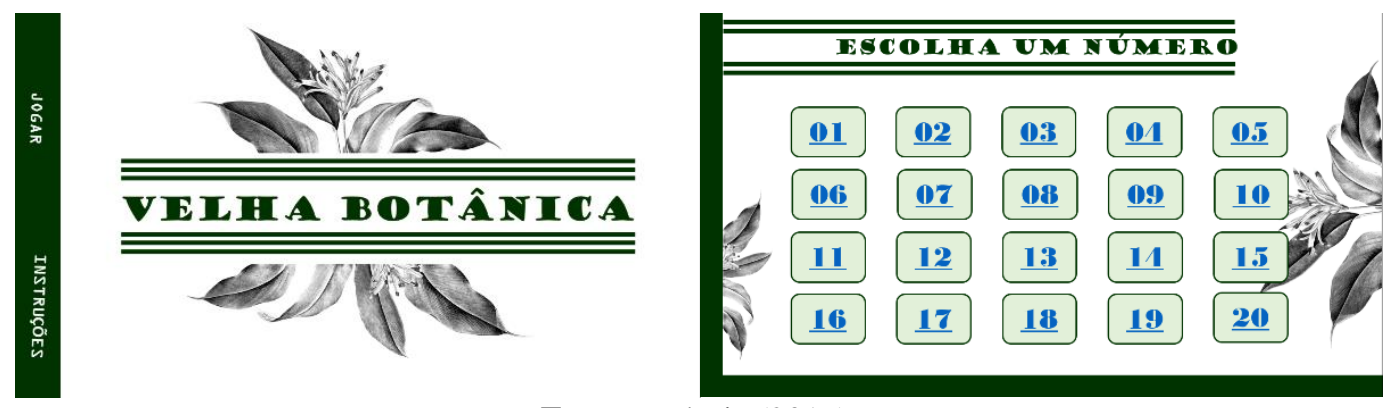

Fonte: Própria (2019).

O jogo foi construído no programa PowerPoint e apresentava 20 questões sendo todas objetivas embasadas no conteúdo abordado, as perguntas apresentavam quatros alternativas A, B, C e D (Figura 2). O intuito do jogo é servir de instrumento que leva os alunos por uma viagem virtual pelo mundo da botânica e seus grupos vegetais e que possibilita aos alunos testarem seus conhecimentos adquiridos e aprendidos durante as aulas anteriores, de maneira dinâmica, divertida e inovadora.

Figura 2 - Perguntas do jogo didáticos velha botânica.

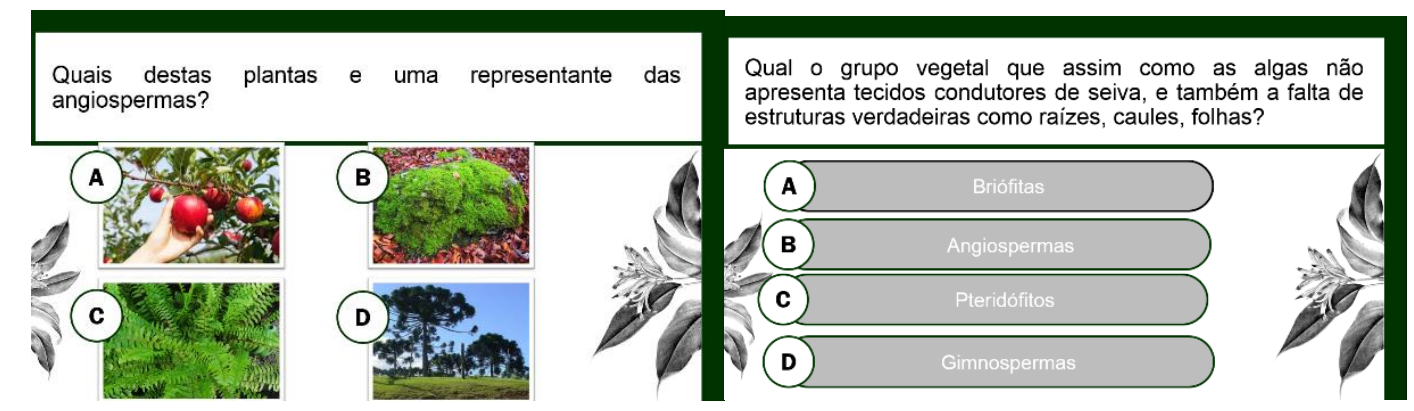

Fonte: Própria (2019)

Os alunos foram divididos em 2 grupos, após esta divisão dos grupos foram ditas as regras do jogo, onde cada grupo escolheria um jogador para representar seu grupo. O jogador em questão escolheria um número que designaria a uma pergunta no jogo, caso o jogador 
respondesse a pergunta escolhida corretamente, colocaria um ponto preto ou branco no tabuleiro de acordo com a cor escolhida para representar o grupo (Figura3). Ao término do jogo foi aplicado pós-questionário para os alunos responderem.

Figura 3 - Aplicação do jogo didático em sala de aula e o tabuleiro utilizado.

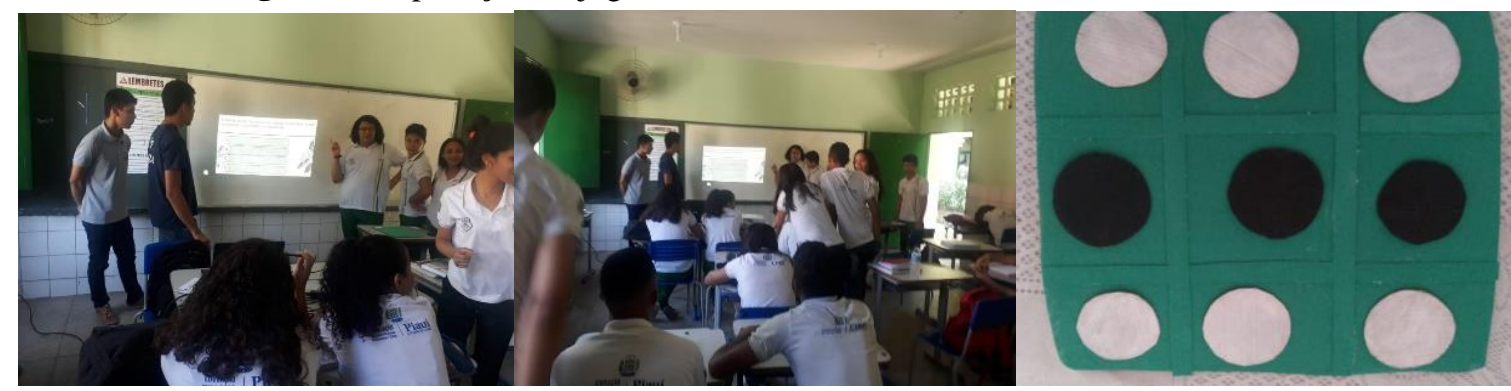

Fonte: Própria (2019)

\section{RESULTADOS E DISCUSSÃO}

Durante aplicação do jogo didático foi possível observar que os alunos estavam bem animados e curiosos para atividade lúdica, durante o decorrer da atividade os mesmos estavam bem participativos e comunicativos, em alguns momentos esclarecendo eventuais dúvidas que surgiam durante a aplicação do jogo.

De acordo com as Orientações Curriculares para o Ensino Médio (BRASIL, 2006), o jogo oferece o estímulo e o ambiente propícios que favorecem o desenvolvimento natural e criativo dos alunos e permite a interatividade entre aluno e professor expandir seus conhecimentos de métodos e técnicas ativas de ensino, desenvolvendo capacidades pessoais e profissionais para estimular nos alunos a competência de comunicação e iniciativa, mostrando uma nova maneira, lúdica, prazerosa e participativa de aprender os conteúdos, levando uma maior acomodação e a apropriação de novos conhecimentos.

No que se refere ao conhecimento dos alunos sobre o grupo de plantas que não apresenta vasos condutores de seiva, no pré-teste 17 alunos apontaram as briófitas como alternativa correta, após a aplicação do jogo 18 alunos que compreenderam que as briófitas são plantas avasculares (Figura 4). Segundo Raven (2007), as briófitas são plantas pequenas, crescem em locais úmidos e não apresentam tecidos de condução de seiva, chamados de xilema e floema, estes só estão presentes nas plantas vasculares. De acordo com Wolski e Tolomeotti (2013), a utilização de metodologias diferenciadas que busque a participação ativa do aluno no processo ensino aprendizagem, e extremamente importante, logo porque, a interação proporcionar aos alunos uma aprendizagem significativa.

Segundo Chaves (2015), o jogo didático como estratégia de ensino no contexto da sala aula só tem a contribuir nos estímulos positivos aos estudantes em revisar o conteúdo abordador 
pelo professor. Portanto, a influência que os jogos didáticos tem sobre os alunos é bastante positiva para o processo de ensino e aprendizagem.

Figura 4. Avaliação do conhecimento dos alunos da 2 a série do Ensino Médio da Escola Estadual Fauzer Bucar, Floriano (PI) sobre as plantas avasculares.

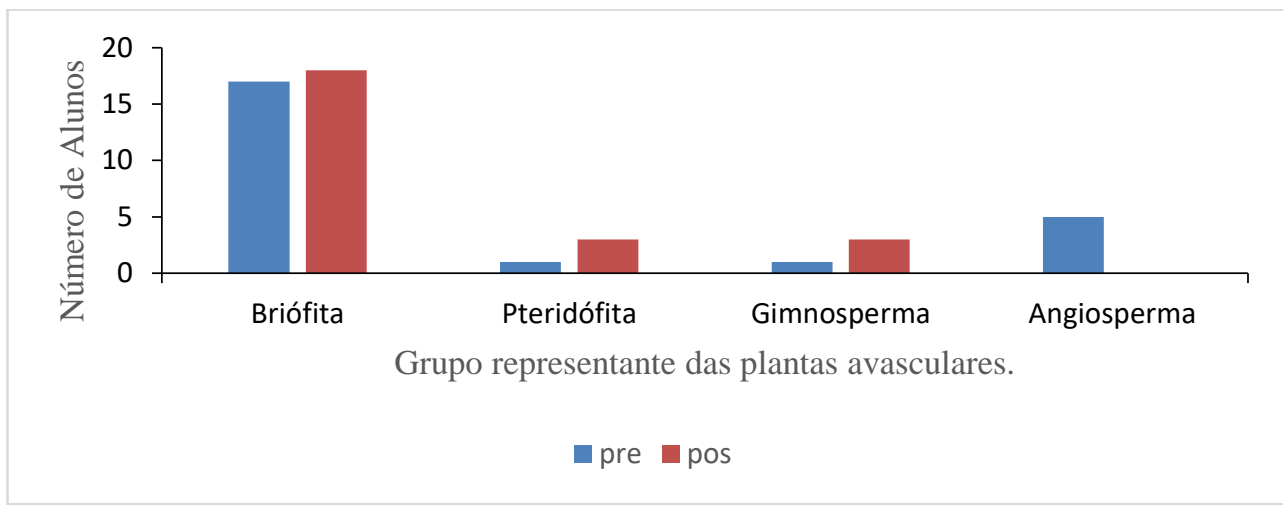

Fonte: Dados da Pesquisa (2019).

Em relação aos conhecimentos sobre o grupo de plantas que apresenta vasos condutores de seiva, não produzem sementes e tem como geração dominante a esporofítica, após a aplicação do jogo, houve um pequeno aumento de 18 alunos que indicaram corretamente as pteridófitas como resposta correta (Figura 5), confirmado assim que estes grupos de plantas vasculares sem sementes que apresenta tecidos condutores de seiva, xilema e floema em sua estrutura (RAVEN et al., 2007).

Figura 5. Avaliação do conhecimento dos alunos da $2^{\mathrm{a}}$ série do Ensino Médio da Escola Estadual Fauzer Bucar Floriano (PI) sobre plantas vasculares sem semente.

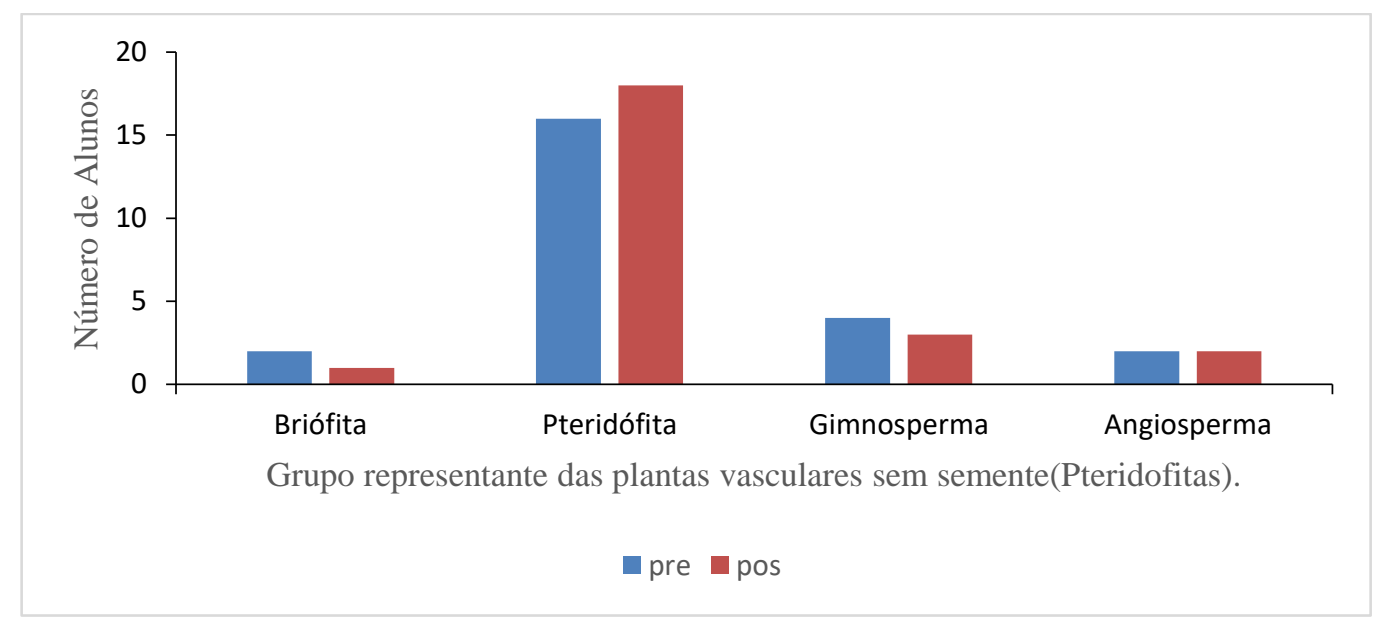

Fonte: Dados da Pesquisa (2019).

Vale destacar que após a utilização do jogo didático houver uma melhora, os 18 alunos apontaram as pteridófitas como plantas que apresenta vasos condutores de seiva. Os jogos 
didáticos influenciam de maneira significativa na construção do conhecimento e facilitando o entendimento dos alunos sobre o conteúdo de difícil compreensão. Segundo Pedroso (2009), é importante o uso de atividades lúdicas como meios de fornecer aos alunos um ambiente agradável, que possibilite o desenvolvimento de habilidades, além de motivar os alunos a participar e a cooperarem diretamente na construção do seu próprio conhecimento

Sobre os conhecimentos prévios dos alunos sobre o grupo vegetal que apresenta fruto no pré-teste 18 alunos relataram que eram as angiospermas que apresenta frutos como característica deste grupo e 6 alunos consideraram que as pteridófitas e as gimnospermas apresentam frutos como características (Figura 6).

Figura 6. Avaliação do conhecimento dos alunos da $2^{\mathrm{a}}$ série do Ensino Médio da Escola Estadual Fauzer Bucar Floriano (PI) sobre os frutos são importantes estruturas, relacionadas a qual dos grupos vegetais.

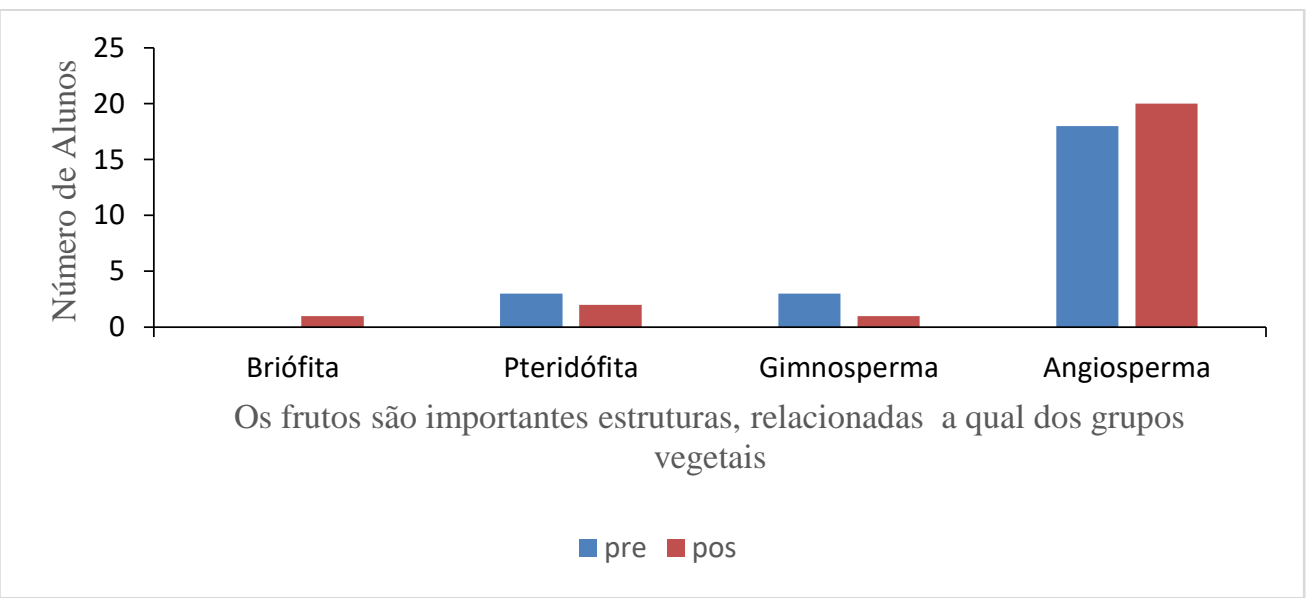

Fonte: Dados da Pesquisa (2019).

Depois da aula com a utilização do jogo didático, 20 alunos apontaram no pós-teste que era as angiospermas. De acordo com Raven (2007), as angiospermas representam um grupo de plantas que tem como característica a flor, fruto e um ciclo de vida que as diferem de todas as outras plantas. Ao verificar que a maioria dos alunos acertaram tanto no pré e pós teste, podemos afirmar que o jogo didático só tem a acrescentar no entendimento e compreensão dos alunos. Portanto, os jogos didáticos têm como finalidade preencher as dúvidas deixadas pelos professores como decorrência de uma educação parada. Segundo Rocha e Rodrigues, (2018), a utilização de um jogo didático e extremamente positiva para o desenvolvimento coletivo, favorecendo a socialização com os colegas, além de colaborar para a construção de novos conhecimentos. Do mesmo modo, para Wolski e Tolomeotti (2013), a proposta de desenvolver novas metodologias de caráter lúdico que busque novos contextos de interação entre aluno e professor e de fundamental importância para o ensino de biologia, logo este tipo de ferramenta que proporciona a colaboração em grupo, e assim promovendo a interatividade e compreensão 
de conceitos.

Com relação opinião dos alunos sobre a utilização do jogo didático se contribuiu para a sua aprendizagem (figura 7), verificou-se que os 23 alunos destacaram que o jogo contribuiu para entendimento do conteúdo abordador no jogo. Segundo Fortuna (2003), destacar a importância da utilização de jogos didáticos no ensino, sendo que o ato de joga desenvolve no aluno a iniciativa, imaginação, raciocínio, a memória, a atenção e a curiosidade e interesse durante uma atividade em sala de aula. Os jogos como recurso didático podem ser instrumento educacional valioso que estimulam os alunos ao maior interesse, facilitando e contribuindo no processo de ensino e aprendizagem, contudo, desde que seja de utilizado de maneira correta pelo professor.

Figura 7. Avaliação do conhecimento dos alunos da $2^{a}$ série do Ensino Médio da Escola Estadual Fauzer Bucar Floriano sobre a contribuição do jogo para a aprendizagem, 2019.

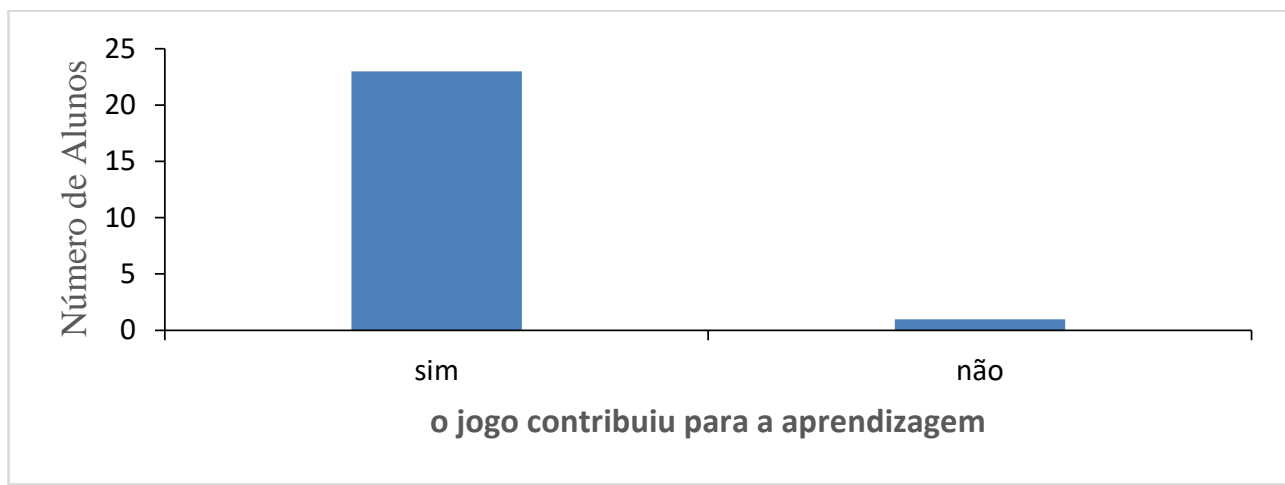

Fonte: Dados da Pesquisa (2019).

De acordo com Wolski e Tolomeotti (2013), “jogos didáticos são um recurso didático lúdico que estimula as várias inteligências, permitindo que o aluno se envolva em tudo que esteja realizando de forma significativa", esta afirmação nos permite concluir que um ambiente com estas características ajuda os alunos, e até mesmo os próprios alunos acabam pedindo formas mais empolgantes e diversificadas que contribuam para este tipo de ambiente. Em relação a isso os alunos foram questionados sobre se preferem aprender com jogos ou exercícios tradicionais, todos os alunos acabaram afirmando que preferem aprender com jogos didáticos do que exercícios tradicionais.

\section{CONCLUSÕES}

A partir dos resultados obtidos da pesquisa demostraram que a partir da utilização do jogo didático "Velha Botânica", evidenciam um bom aproveitamento do recurso didático, observando que o jogo favoreceu aos alunos uma maior assimilação do conteúdo relacionado a 
introdução a botânica. $\mathrm{O}$ avanço no bom desempenho por parte dos alunos se deu a partir da contextualização da atividade da realizada, proporcionando uma aula mais interativa, dinâmica, participativa, motivadora e estimulante. Pois, após aplicação do jogo didático os alunos conseguiram identificar as características dos grupos plantas avasculares e vasculares, compreendendo que as briófitas são plantas avasculares e pteridófitas plantas vasculares sem sementes, além da importância do fruto como característica evolutiva das angiospermas.

Portanto, foi possível verificar que atividades lúdicas tem a função primordial de fazer com que os alunos, sejam mais ativos e participativos durante a aula. Destaca-se a importância a importância do recurso didático para o aprimoramento da aprendizagem sobre o conteúdo de botânica.

\section{REFERÊNCIAS}

ARAÚJO, G. C. Botânica no ensino médio. Monografia (Licenciatura em Ciências Biológicas) - Consórcio Setentrional de Educação a Distância, Universidade de Brasília, Universidade Estadual de Goiás, Brasília, 2011.

ARAÚJO, J. N. O ensino de botânica em uma perspectiva construtivista. In. IX congresso nacional de educação Edurece.2013. FAPEAM, Curitiba, 2013.

ARRAIS, M. G. M.; SOUSA, G. M.; MARSUA, M. L. A. O ensino de botânica: Investigando dificuldades na prática docente. Revista da Associação Brasileira de Ensino de Biologia, n.7, p. 5409-5418, 2014.

BONFIM, L. R. M.; TAVARES-MARTINS, A. C. C.; PALHETA, I. C.; JUNIOR, A. S. M. O ensino de botânica em escolas públicas e particulares no município de Barcarena, Pará, Brasil. ARETÉ. Manaus, Vol.8, Num.17, p.167-176. jul/dez 2015.

BRASIL. Ministério da Educação. Secretaria de Educação Básica. Orientações Curriculares para o Ensino Médio: Ciências da natureza, matemática e suas tecnologias. Brasília: MEC/SEB, 135 p. 2006.

CHAVES, B. E.; et al. Ludo Vegetal: uma nova alternativa para a aprendizagem de Botânica. Revista Brasileira de Biociências, Porto Alegre, v. 13, n. 3, 2015.

DA SILVA, R. F.; CORREA, E. S. Novas tecnologias e educação: A evolução do processo de ensino e a aprendizagem na sociedade contemporânea. Educação \& linguagem. Num.1, p. 2335.mar/maio 2014.

ESTRELA, M. N.; VIANA, G. C. S.; SANTANA, J. C. S. O ensino de botânica de uma forma diferente a partir projeto "BOTÂNICA NA ESCOLA" da sala de ciências do SESC-PB. In. Congresso nacional de educação CONEDU. Pernambuco, 2017.

FORTUNA, T. R. Jogo em aula: recurso permite repensar as relações de ensino aprendizagem. 
Revista do Professor, Porto Alegre, v. 19, n. 75, p. 15-19, 2003.

MARTINS-DA-SILVA, R. C. V.; SILVA, A. S. L.; FERNANDES, M. M.; MARGALHO, L. F. Noções morfológicas e taxonômicas para identificação botânica. Embrapa, Brasília, DF, 2014.

MELO, E. A; ABREU, F.F; ANDRADE, A. B; ARAÚJO, M. I. O. A aprendizagem de botânica no ensino fundamental: Dificuldades e desafios. Revista SCIENTIA PLENA, Sergipe, Vol.8, Num.10, p. 1-8, 2012.

MELO, J. F. R. Desenvolvimento de atividades práticas experimentais no ensino de biologia - um estudo de caso. 75 f. Dissertação (Mestrado Profissional em Ensino de Ciências) - Universidade de Brasília, Brasília, 2010.

MOUL, R. A. T. M.; DA SILVA, F. C. L.. A construção de conceitos em botânica a partir de uma sequência didática interativa: proposições para o ensino de ciências. Revista Exitus. Santarém, Vol. 7, Num. 2, p. 262-282, Maio/Ago 2017.

NEVES, A. L. L. A.; SOUSA, G. M; ARRAIS, M. G. M. A produção de jogos didáticos de botânica como facilitadores do ensino de ciências na EJA. Revista da Associação Brasileira de Ensino de Biologia, São Paulo, v. 1, n. 7, p. 553-563, 2014.

NICOLA, Jéssica Anese; PANIZ, Catiane Mazocco. A importância da utilização de diferentes recursos didáticos no ensino de biologia. A InFor, Inovação e Formação, Revista do Núcleo de Educação a Distância da Universidade Estadual Paulista - NEaD/Unesp , São Paulo, v. 2, n. 1, p.355-381, 2016. ISSN 2525-3476.

PEDROSO, C. V. Jogos didáticos no ensino de biologia: uma proposta metodológica baseada em módulo didático. In. IX Congresso Estadual de Educação-EDUCERE; III Encontro Sul Brasileiro de Psicopedagogia. 2009.

RAVEN, Peter H.; EVERT, Ray F.; EICHHORN, Susan E. Biologia Vegetal. 7. ed. Rio de Janeiro: Guanabara Koogan, 2007.

ROCHA, D. F. da; RODRIGUES, M. da S. Jogo didático como facilitador para o ensino de BIOLOGIA no ensino médio. Revista cippus - Unilasalle,Canoas, RS, v. 8 n. 2 , novembro, 2018.

SALATINO, A. BUCKERIDGE, M. Mas de que te serve saber botânica. Instituto de Biociências, Universidade de São Paulo, São Paulo, 2016.

SANTANA, A. O. R.; CASASCO, E. F. C.; SESSA, P.. Modalidades didáticas no ensino de ciências: O olhar de estudantes da educação básica sobre o processo de aprendizagem. Revista da Associação Brasileira de Ensino de Biologia. [S.L.] Núm. 9. p. 841- 8512016.

SANTOS, E. A. V.; NETO, L. S. Dificuldades no ensino-aprendizagem de botânica e possíveis alternativas pelas abordagens de educação ambiental e sustentabilidade. [S.L.:S.N], 2017.

SILVA, J. N; GHILARDI-LOPES, N.P. Botânica no Ensino Fundamental: diagnósticos de 
AVELINO, et al

dificuldades no ensino e da percepção e representação da biodiversidade vegetal por estudantes. REEC: Revista electrónica de Enseñanza de las Ciencias, v. 13, n. 2, p. 115-136, 2014.

WOLSKI, B. Z D.; TOLOMEOTTI, K. R. B. Atividades lúdicas de aprender e brincar com as células. Cardenos PDE, Paraná, vol 1, 2013 